
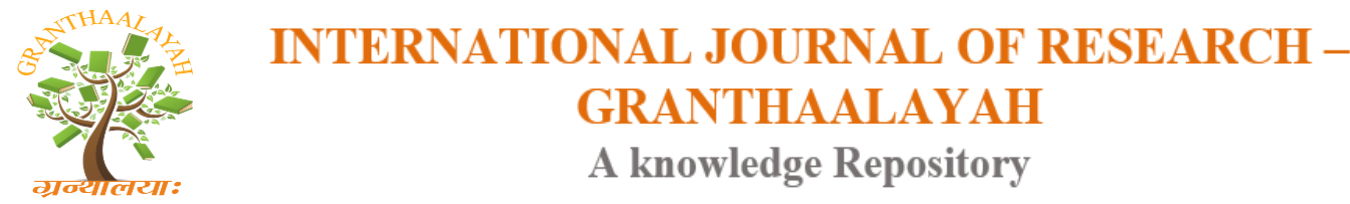

Management

\title{
INFORMATION SEEKING BEHAVIOR AND ITS PRACTICAL UTILITY
}

\author{
Versha Bharadwaj ${ }^{* 1}$, Dr. Javed Khan ${ }^{2}$ \\ ${ }^{* 1}$ Research Scholar, Swami VivekanandSubharti University, Meerut, INDIA \\ ${ }^{2}$ Associate Professor, Swami VivekanandSubharti University, Meerut, INDIA
}

DOI: https://doi.org/10.29121/granthaalayah.v4.i10.2016.2491

\section{ABSTRACT}

Information behaviour is also the term of art used in library and information science to refer to a sub-discipline that engages in a wide range of types of research conducted in order to understand the human relationship to information. Information seeking behavior refers to those activities a person engages in when identifying his or her own need for information, searching for such information in any way and using or transferring of information.

The term information seeking often serves as an umbrella overarching a set of related concepts and issues. In the library world, discussions of database construction and management, community information needs, reference services, and many other topics resonate with the term.

Keywords:

Academic Libraries, Information behaviour, Technology.

Cite This Article: Versha Bharadwaj, and Dr. Javed Khan, "USE OF INFORMATION SOURCES AND SERVICES IN ACADEMIC LIBRARIES" International Journal of Research Granthaalayah, Vol. 4, No. 10 (2016): 58-64.

\section{INTRODUCTION}

\section{CONCEPT OF INFORMATION AND INFORMATION BEHAVIOR}

The term 'Information' originated from 'formation' and forms both these terms define the size and format of any entity, along with the indication towards the construction of a pattern.

"Information behaviour" is the currently preferred term used to describe the many ways in which human beings interact with information, in particular, the ways in which people seek and utilize information. Information behaviour is also the term of art used in library and information science to refer to a sub-discipline that engages in a wide range of types of research conducted in order to understand the human relationship to information. 


\section{INFORMATION NEEDS AND SEEKING BEHAVIOR}

Information seeking behavior refers to those activities a person engages in when identifying his or her own need for information, searching for such information in any way and using or transferring of information. Information behavior is the totality of human behavior in relation to the sources and channels of information, including both active and passive information seeking and information use. Thus it includes face to face and online communication with others as well as the passive reception of information. Information seeking behavior involves personal reasons for seeking information, the kinds of information which are being sought and the ways and sources with which needed information is being sought. Information seeking behavior is expressed in various forms, from reading printed material to research and experimentation. Scholars, students and faculties actively seek current information from the various media available in libraries, for example encyclopedias, journals and more currently, electronic media.

According to Wilson, information seeking behavior results from the recognition of some need, perceived by the user. That behavior may take several forms: the user may make demands upon formal systems that are services, information centers; or upon systems which may perform information functions in addition to primary, non-information functions such as estate agent's offices or car sales agencies that give current information of their field viz., prices and models etc. The user also seeks information from other people which is otherwise called information exchange'. According to him the word 'exchange' is intended to draw attention to the element of reciprocity, recognized by Sociologists and Social Psychologists as a fundamental aspect of human interaction. In the process failure may be experienced with systems as well as when seeking information from others. Use of information according to him is evaluation to discover its relationship to the user's need.

\section{INFORMATION SEEKING BEHAVIOR}

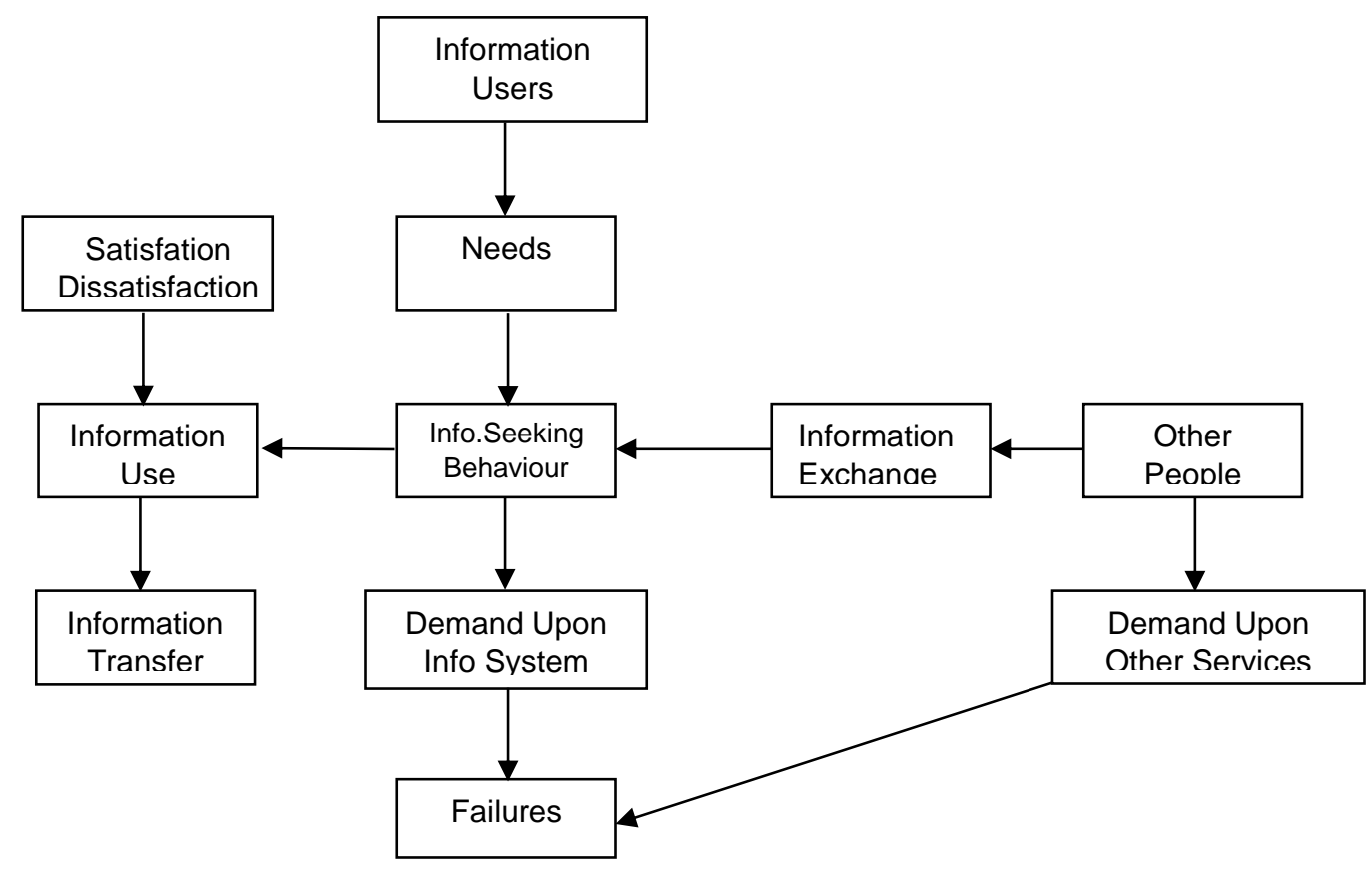


The term information seeking often serves as an umbrella overarching a set of related concepts and issues. In the library world, discussions of database construction and management, community information needs, reference services, and many other topics resonate with the term. Yet, a single, serviceable definition remains elusive.

Like any other complex concept, information seeking means different things in different contexts. In the simplest terms, information seeking involves the search, retrieval, recognition, and application of meaningful content. This search may be explicit or implicit, the retrieval may be the result of specific strategies or serendipity, the resulting information may be embraced or rejected, the entire experience may be carried through to a logical conclusion or aborted in midstream, and there may be a million other potential results.

\section{IMPLICATIONS}

Girja Kumar has emphasized that the information seeking behavior is mainly concerned with who needs what kind of information for what reason; how information if found, evaluated and used, and how their needs can be identified and satisfied. According to him the following process takes place in the information seeking behavior.
a. Identifying objective
b. Defining need
c. Accessing information system
d. Establishing sources of information
e. Information acquisition
f. Use of information
g. Satisfaction/Dissatisfaction

The information seeking behaviour essentially refers to the strategies and action undertaken to locate discrete knowledge elements. It is concerned with integrative utilization of three basic resources: (i) people (ii) information, and (iii) system. It can be said that the behaviour, which yields the highest information satisfaction, is the best.

Information use studies over the years have attempted to explain the information use phenomenon, to understand information use behaviour and improve information use by manipulating essential conditions. Information seeking behaviour results from the recognition of some need experienced by the user. This behaviour may take several forms, e.g. user may make demands upon formal systems which may perform information function in addition to a primary non-information function. Over the years there has been a change in the understanding of the use behavior.

More recently Wilson in his model of factors influencing the needs and information seeking behavior opines that the full range of human personal needs such as physiological, affective and cognitive needs are at the root of motivation towards information seeking behavior. 


\section{PSYCHOLOGICAL STUDIES RELATED TO INFORMATION SEEKING BEHAVIOR}

Many studies in the past have stressed on the psychological aspect of the information seeking behavior.

Taylor has explored the information need from the angle of psychology of human behavior, and has identified four levels of information need as follows:
a. Visceral need:-
An actual but unexpressed need for information.
b. Conscious need:-
An ill-defined area of decision.
c. Formal need:-
An area of doubt which may be expressed in concrete terms.
d. Comprised need:-
A need translate into what the resources and the file can be deliver.

\section{USE OF INFORMATION SEEKING PATTERN}

Information use patterns are paths pursued by the individuals in the attempt to resolve a need. A study of user traits, of the study environment, and of information provider's skills, is an important constituent of this new systematic approach. Chin-chin Chen has remarked that the information seeking patterns of an individual information environment, which consists of:
a. Background and characteristics of the individual.
b. b. The nature and type of information need with which he/she is confronted.
c. The type and availability of information providers.
d. Information provider's capability of responding to a request.
e. Existence of barriers that serve to diminish or defect the effective linkage between information provider and seeker; and
f. The degree and satisfaction perceived by an individual with the ability of one and more information providers to respond to his/her information needs.

\section{FACTORS INFLUENCING INFORMATION SEEKING BEHAVIOR}

The factors that influence the human seeking behavior include.
a. Payoffs and costs
b. Resources available
c. Update rates
d. Amount of information available
e. Diagnosticity of data
f. Distributional characteristics of data
g. Conflicts among sources 
It may be emphasizes that a correct appraisal of information seeking behavior implies knowledge of:
a. The purpose for which information is required.
b. Environment in which user operate
c. User's skill identifying information need and information provider's skill in providing information.
d. Channels and sources for taping the information, and
e. Barriers to information.

\section{USER APPROACH TO INFORMATION}

Information need is a composite concept, which is generally dynamic in users. The information requirement is generally affected by various factors like purpose of his work, stage of his work, diversity of interest. According to Melvin Voigt the user's different approaches to meet information requirements are current approach. Everyday approach, Exhaustive approach and catching up and brushing up approach. The current approach is that users want to keep themselves abreast of nascent developments in their field of interest. Everyday approach is sought to satisfy the specific piece of information required by the user, during day to date investigation in the form of facts. The exhaustive approach is sought to at when a researcher wants comprehensive details about a specific topic on the field of study. Catching up approach is adopted in situations where a particular user requires information pertaining to relate subject fields.

\section{INFORMATION USER STUDIES}

Information user studies over the years have attempted to explain the information use phenomena, to understand information use behaviour, to predict this behaviour, to control and improve the information use by manipulating essential conditions. One of the preliminaries to the attainment of this objective is the description of user behaviour in many aspects \{Ford, 1977\}.

Information seeking behaviour results from the recognition of some need experienced by the user. That behaviour may take several forms, e.g. user may make the demands upon formal systems (libraries) or upon systems which may perform the information function in addition to a primary non information function. Alternatively the user may seek information from other people. In this context user studies do not aim to pattern information seeking behaviour, but to draw interrelationships among concepts used in the field.

\section{PRACTICAL UTILITY OF INFORMATION SEEKING BEHAVIOUR}

Despite the doubts expressed regarding the user's ability to convey their needs investigations concerning user needs have been pursued for their practical value. Paisley has pointed out that the earliest studies of information' needs and uses took place within libraries-, information centers and laboratories because librarians and administrators needed data for service decisions. Later many studies were sponsored by professional associations, American institute of physics, for the learned associations in general were examining their information explosion and the new 
technology. Thus, the vast majority of user studies in science and technology fall in to one of the following categories: study of information requirements of a particular discipline like physics, chemistry, etc., or the ones limited to a particular research establishment or industry where they exit across subject boundaries.

Information needs of individuals in an organization differ depending upon their respective functions and tasks, the level of their knowledge and experience (in the specific field of specialization and in the use of information systems and services), their particular interest and need to satisfy which they seek information, on the breadth and depth of their interest profiles, and on the nature of the subject or field of specialization or interest.

Information needs can be difficult to quantify. It can be best measured through information seeking or information use situations.' Information need' is an abstract concept, used to answer the query why people seek, gather and use information

\section{USER STUDIES AND THEIR USEFULNESS}

The user studies, information-need studies, use studies; information transfer studies, communication behaviour studies, information behaviour studies, dissemination and utilization studies are closely related. When approached from the point of view of the scientist or technologist, these are studies of science communication behaviour. When approached from the point of view of the science communication system, they are studies in the flow of information among scientists and technologists. Hence the terminology depends much on the approach and the angle from which one sees. Some motives and purposes of users give rise to information needs requirements. To satisfy such needs and requirements users adopt many ways and means of accessing and searching sources of information.

The factors/variables that affect information transfer process and user behaviour are innumerable and any empirical study has to make its own assumptions to simplify the situation (Old man). A model of information seeking activities of scientist and his research group presented by Orr provided a fairy exhaustive list factors that affect the scientist's information seeking behaviour. He asserts that any particular type of communication behaviour must be assessed in relation to all other communication behaviours.

Information needs - the type, coverage, depth - of a user may differ considerably depending upon the his/her activity at the moment - for instance, when entering a new field of research as compared to when seeking a solution to a specific problem in a field already familiar to the person. An information seeking behaviour of a user may result from the recognition of some information need.

\section{REFERENCES}

[1] Borgman, C.L., Hirsh, S.G., \& Hiller, J. (1996). Rethinking online monitoring methods for information retrieval systems: From search product to search process. Journal of the American Society for Information Science, 47(7), 568-583. 
[2] Kakai, J.M., Ikoja-Odongo, R., \&Kigongo-Bukenya, I.M.N. (2004) A study of the information seeking behavior of undergraduate students of Makerere University, Uganda. World Libraries 14 (1)

[3] Kumar (Krishna) (2003). Sources of information reference service. New Delhi. Vikash publishing house PVT L TD, 115-128.

[4] Kumar (PSG) (2004). Information seeking behavior of Library \& users. Delhi B.R. publishing 60-68.

[5] Singhal K.P. and Gautam J.N. (2005) Information seeking behavior of PG Students studying in Professional courses (MM (PG) College, Modinagar) and study with reference to their library use, library heraid.43 (2); 92-108.

[6] Wilson, T.D.(1999). Models in information behavior in research Journal of Documentation 55 (3): 249-270. 